\title{
PERAN MEDIASI EMOTIONAL EXHAUSTION PADA PENGARUH WORK LIFE $B A L A N C E$ TERHADAP KEPUASAN KERJA KARYAWAN WANITA DI UNIVERSITAS NEGERI SURABAYA
}

\author{
Cici Novita Sihaloho \\ Universitas Negeri Surabaya \\ cicinovita79@gmail.com \\ Nurul Indawati \\ Universitas Negeri Surabaya \\ nurulindawati@Unesa.ac.id
}

Abstract

The factors that influence employee job satisfaction are work-life balance and emotional exhaustion. Factors that can affect job satisfaction will affect employee job satisfaction. This study aimed to determine the influence of work-life balance on job satisfaction through emotional exhaustion. This research was conducted at Surabaya State University, with a total sample of 60 employees and used convenience sample techniques. Data collection uses surveys, interviews, and questionnaires. Data analysis techniques using PLS (Partial Least Square). The results of the study show that work-life balance has a positive effect on job satisfaction, while emotional exhaustion harms job satisfaction.

Keywords: emotional exhaustion; job satisfaction; organizations; women employee; work-life balance.

\section{PENDAHULUAN}

Pada saat ini peran wanita tidak hanya dengan pekerjaan rumah tetapi juga berkaitan dengan karir di luar rumah (Darmawan et.al., 2015). Hal ini dipengaruhi oleh perkembangan zaman yang menuntut wanita untuk memiliki sifat mandiri, keinginan untuk mengembangkan diri, serta keinginan untuk menjalani kehidupan pribadi dengan merintis karir di dunia kerja. Berdasarkan data dari Badan Pusat Statistik (BPS), pada tahun 2018 partisipasi pekerja wanita mengalami peningkatan sebesar 0,40 persen dari tahun sebelumnya atau dari jumlah populasi pekerja di Indonesia tahun 2018 sebanyak 133,94 juta jiwa dan sebanyak 55,44 juta jiwa adalah pekerja wanita dibanding tahun sebelumnya yang hanya berjumlah 50,89 juta jiwa (BPS. 2018).

Wanita karir yang sudah menikah menghasilkan peran ganda baginya di antaranya sebagai ibu rumah tangga dan wanita karir, hal tersebut dijelaskan oleh Aldous (Nasekhah, 2017). Work life balance merupakan faktor-faktor yang diidentifikasi sebagai faktor yang memengaruhi kepuasan kerja (Rifadha, 2015 dalam Shabrina dan Ratnaningsih, 2019). Yunita (2018) menjelaskan bahwa tingginya tingkat kepuasan kerja dihasilkan pula dari tingginya tingkat work life balance, tingginya komitmen seseorang terhadap organisasinya dan rendahnya tingkat turnover. Pengembangan karir yang baik merupakan faktor penentu di mana karyawan merasa puas akan pekerjaannya di suatu organisasi, dan tingginya tingkat work life balance dari tiap-tiap karyawan (Asepta \& Maruno, 2017).

Work life balance adalah keadaaan di mana individu dapat menyetarakan maupun mengatur tuntutan pekerjaaan dan kehidupan pribadi (Moorhead dan Griffin, 2013). Penelitian sebelumnya yang dilakukan Machuca et al.(2015) menjelaskan bahwa keseimbangan kehidupan kerja karyawan secara positif terkait dengan kebanggaan organisasi dan job satisfaction. Hal tersebut didukung oleh penelitian Nurendra \& Saraswati (2016) yang menyatakan bahwa keseimbangan kehidupan kerja adalah aspek penentu yang memengaruhi kepuasan kerja karyawan, tingginya tingkat kepuasan seorang karyawan dalam suatu organisasi dipengaruhi pula oleh tingginya tingkat work life balance.

Maslichah \& Hidayat (2017) menyatakan bahwa keseimbangan kehidupan kerja yang baik dalam pekerjaan akan menghasilkan perasaan puas terhadap pekerjaan itu sendiri, timbulnya rasa penuh tanggung jawab dalam kehidupan pribadi maupun pekerjaannya serta menimbulkan tingginya 
samangat untuk bekerja. Hal ini dapat dibuktikan dengan penelititan yang dilakukan oleh Asepta \& Maruno (2017), bahwa work life balance memengaruhi kepuasan kerja dengan positif signifikan.

Menurut Son \& Jung (2019) menyebutkan bahwa keseimbangan kehidupan kerja karyawan berpengaruh negatif pada job satisfaction. Pendapat lain yang dikemukakan oleh Arunika et al. (2015) mengatakan bahwa keseimbangan kehidupan kerja secara negatif memiliki pengaruh ke kepuasan kerja karyawan Non Eksekutif Sektor Perbankan Publik di Distrik Colombo. Ganaphati et al. (2016) menyatakan bahwa keseimbangan kehidupan kerja tidak berpengaruh secara parsial secara parsial ke job satisfaction.

Pencapaian kepuasan kerja juga dipengaruhi tantangan lain seperti emotional exhaustion. Kelelahan emosional (emotional exhaustion) menyebabkan frustasi terhadap karyawan. Kelelahan emosional berdampak negatif pada organisasi maupun individu (Mujiatun et al., 2019). Bruce (2009) mengatakan burnout memiliki berbagai dimensi salah satunya adalah emotional exhaustion. Kelelahan emosional sendiri merupakan kelelahan secara emosi dan perasaan seseorang terhadap orang lain. Sumber kelelahan dapat berasal dari keselamatan kerja karyawan yang masih kurang, jumlah staf, material, peralatan yang belum memadai, jam kerja yang panjang dan lain-lain yang tidak memadai, politik serta masalah ekonomi yang dapat mengakibatkan kelelahan kerja akibat kurangnya kepuasan kerja yang dimiliki oleh karyawan (Yuksel et al., 2016). Timbulnya tuntutan dalam pekerjaan mengakibatkan tidak stabilnya emosi karyawan karena ketidakseimbangan antara pekerjaan dan keluarga yang berakibat pada menurunnya kinerja, hal itu dijelaskan oleh (Karatepe dalam Hadi, 2013).

Kelelahan emosional disebabkan stres berlebih atau karyawan merasa bahwa pekerjaan yang dilakukan tidak membuat karyawan merasa puas, (Cherniss, 2001 dalam Christianto \& Putra, 2016). Adapun sumber lain mengungkapkan tuntutan pekerjaan dan peran menimbulkan karyawan mudah mengalami kelelahan emosional (Jarsvelt, 2010 dalam Christianto \& Putra, 2016) Penelitian yang dilakukan oleh Yuliastini \& Putra (2015) menjelaskan bahwa emotional exhaustion signifikan negatif memengaruhi kepuasan kerja guru SMK di Denpasar. Hasil penelitian lainnya mengatakan bahwa kepuasan kerja dipengaruhi secara negatif signifikan melalui kelelahan emosional (Christianto \& Putra, 2016).

Menurut Safrida et al. (2016), kelelahan emosional berpengaruh positif pada kepuasan kerja guru SMP 2 Medan. Hasil penelitian lain yang dikemukakan oleh Tuğsal (2017) mengatakan bahwa keseimbangan kehidupan kerja berpengaruh negatif ke emotional exhaustion. Penelitian ini bertujuan menganalisis peran mediasi emotional exhaustion pada pengaruh work life balance terhadap kepuasan kerja karyawan wanita di Universitas Negeri Surabaya.

\section{KAJIAN PUSTAKA DAN PENGEMBANGAN HIPOTESIS}

\section{Work Life Balance (X1)}

Work-life balance merupakan suatu pilihan dalam pengelolaan di dalam bekerja dan tanggung jawab pada pribadi atau keluarga dari sisi karyawan. Sedangkan pandangan work life balance dari perusahaan adalah menciptakan budaya yanga merupakan suatu tantangan yang mengharapkan karyawan untuk fokus bekerja di tempat kerja atau di perusahaan guna mendukung tujuan perusahaan (Mardhatillah \& Santoso, 2019).

Work life balance merupakan tingkat pencapaian seseorang individu akan kepuasan kerja atas keterlibatannya terhadap kehidupan pribadi dan pekerjaan yang dimiliki dalam kehidupannya dan dilakukan semaksimal mungkin (Lazar et al., 2010). Ganapathi et al. (2016) juga berpendapat bahwa keseimbangan kehidupan kerja merupakan suatu kepuasan individu akan pencapaian keseimbangan kehidupan dan pekerjaannya.

Menurut Kirchmeyer dalam Pouluse \& Sudarsan (2014), keseimbangan kehidupan kerja merupakan 
Cici Novita Sihaloho \& Nurul Indawati. Peran Mediasi Emotional Exhaustion pada Pengaruh Work Life Balance terhadap Kepuasan Kerja Karyawan Wanita di Universitas Negeri Surabaya

kepuasan individu akan pencapainnya terhadap pengalaman hidup, energi yang berasal dari diri sendiri diperlukan akan pengalaman hidup guna mencapai kepuasan kerja, komitmen dan waktu untuk terlibat saat bekerja.

Menurut Rigby dan Smith (2010) dalam Momani (2017), keseimbangan kehidupan kerja berdasarkan prioritas mernjelaskan manajemen waktu saat bekerja dan sebagai individual atau pribadi, artinya ada kejelasan indikasi dalam pembagian waktu, yaitu kehidupan sebagai seorang individual dan kehidupan sebagai karyawan saat bekerja di kantor. Keseimbangan kehidupan kerja diidentifikasi merupakan tantangan dalam menciptakan sportifnya lingkungan kerja agar karyawan fokus dan bekerja ekstra lebih guna tercapainya tujuan organisasi di tempat kerja tersebut jika dilihat dari pandangan suatu organisasi. Pengambilan tindakan dan keputusan dapat dipengaruhi oleh keseimbangan kehidupan kerja karena terkait personal life dan perjuangan seorang individu guna memenuhi keseimbangan tersebut sangat berkaitan erat. Work life balance adalah peran ganda bagi individu untuk dikerjakan dan dipenuhi secara bertanggung jawab agar tidak merasa ketidakseimbangan work life balance akan menyebabkan tekanan pada saat bekerja karena hal tersebut sangat penting.

Nafiudin (2015) menjelaskan bahwa ketidakseimbangan work life balance seorang individu mengidentifikasi individu tersebut akan mencari pekerjaan yang lain agar tetap mampu menyeimbangkan kehidupan pribadi dan pekerjaan di kantor atau bahkan karyawan tersebut memutuskan untuk tidak bekerja kembali. Rendahnya tingkat tersebut juga dapat menyebabkan karyawan stres. Dapat diketahui bahwa work life balance merupakan cara seseorang menyeimbangkan waktu di tempat kerja dan diluar untuk menjalankan peran sebagai individu sekaligus bertanggung jawab untuk memenuhi pekerjaannya, hal tersebut diketahui berdasarkan pendapat pari ahli.

Keseimbangan kehidupan dan kerja (work life balance) sering diteliti dikarenakan konsep pembahasannya tidak terbatas di mana hal tersebut berkaitan dengan ditetapkannya suatu kepentingan yang sesuai. Di samping itu, keseimbangan kehidupan pribadi dan pekerjaan mengindikasikan seberapa jauh seorang karyawan merasa bahwa kebutuhan akan pekerjaan maupun hal di luar pekerjaan dapat dipenuhi (Singh \& Khanna, 2011).

Schabracq dan Cooper (2003) mengatakan bahwa work life balance seorang individu kemungkinan dipengaruhi oleh beberapa faktor yaitu karakteristik kepribadian, keluarga, pekerjaan dan sikap. Menurut Langford (2009) ada 4 indikator yang dipakai untuk pengukuran work life balance, yakni keseimbangan waktu di tempat kerja dan di luar kerja, pertanggungjawaban pada perusahaan maupun pada keluarga, dapat bersosialisasi di luar tempat kerja, memiliki waktu untuk melakukan hobi.

\section{Emotional Exhaustion (Z)}

Emotional Exhasution diidentifikasi sebagai salah satu dimensi dari burnout. Burnout merupakan respon individu akibat stress secara emosional maupun interpersonal karena tidak dapat teratasi dalam kurun waktu panjang yang disebabkan oleh pekerjaan (Maslach, Schaufeli \& Leiter, 2001). Kelelahan emosional (Emotional exhaustion), bersikap sinis (cynism), dan sikap menolak untuk bekerja tepat waktu (inefficacy) merupakan tiga dimensi kunci dan respon terhadap burnout (Nujiiya, 2015). Emotional exhaustion memberikan pengaruh yang negatif pada seorang karyawan di saat bekerja, contohnya malas untuk bekerja, mudah kecewa, berpikiran bahwa yang dilakukan saat bekerja adalah sia sia, mudah sakit hati, berkecil hati, dan masa bodoh (ignoring) (Christianto \& Putra, 2016).

Ketidakseimbangan antara pekerjaan dan kehidupan pribadi mengakibatkan krisis emosional yang menimbulkan habisnya sumber emosional. Di samping itu, kelelahan secara emosional yang dialami oleh seorang karyawan mengakibatkan timbulnya kelelahan secara berlebihan, bekerja dengan tidak maksimal, dan tidak mau membantu orang lain. Karyawan yang kelelahan secara emosional bahkan membatalkan pekerjaan, kehilangan rasa senang dalam bekerja, bahkan dalam situasi yang parah kelelahan emosional dapat menimbulkan seseorang/ individu mengalami sakit mental bahkan bunuh diri (Safrida et al., 2015) 
Maslach dan Jackson (1981) menjelaskan bahwa emotional exhaustion merupakan reaksi emosional yang berlebih dan perasaan individu secara emosional yang telah terkuras akibat adanya interaksi seseorang dengan orang lain. Menurut Wright dan Cropanzano (1998), emotional exhaustion dipengaruhi oleh dua indikator yaitu kelelahan fisik dan kelelahan psikologi. Menurut Houkes et al. (2003) emotional exhaustion dipengaruhi oleh empat faktor yaitu tanggung jawab, tekanan waktu, tidak ada dukungan sosial, dan tertekan karena peran. Teori pengukuran kelelahan emosional Sobur (2003), dalam penelitian Babakus et al. (1999), sutjipto 2001), Zagladi (2004), Pines \&Aronson (1989), serta Burke \& Greenglass (1995) menjelaskan bahwa kelelahan emosional dipengaruhi oleh beberapa indikator, di antaranya mudah terprovokasi, merasa terjebak dalam pekerjaan, protes, tidak semangat, bersedih, lemah, di bawah tekanan,cemas, ceroboh, jenuh, dan kelelahan.

\section{Kepuasan Kerja}

Kepuasan kerja diidentifikasi sebagai suatu perspektif individu yang ada kaitannya dengan pemikiran positif maupun negatif akan pekerjaan yang dimiliki (Asepta \& Maruno, 2017). Hal tersebut berbanding lurus dengan Locke (1976) dalam Lie \& Siagian (2018) yang mengatakan bahwa kepuasan kerja adalah suatu respon emosi yang muncul dari evaluasi kerja karyawan atau pengalaman kerja yang bersifat positif. Situasi kerja yang menimbulkan respon emosional, pencapaian yang dicapai atau apakah hasilnya sesuai dengan tujuan awal, dan kepuasan kerja juga menjelaskan perilaku seorang individu dalam tiga dimensi yang ada pada kepuasan kerja

Menurut Maslichah \& Hidayat (2017), kepuasan kerja merupakan rasa menyenangkan yang timbul dari sikap emosional seseorang dan memengaruhi individu agar lebih mencintai pekerjaan yang dikerjakan. Hal tersebut didapatkan melalui kepatuhan, kejujuran saat bekerja dan kinerja saat bekerja. Dengan demikian, perusahaan perlu mengevaluasi kepuasan kerja dari setiap karwayan, karyawan yang merasa tidak puas akan pekerjaan yang dikerjakan akan menimbulkan perasaan untuk meninggalkan pekerjaannya, melakukan komplain, tidak memiliki sikap penurut pada perusahaan, tidak bertanggung jawab terhadap pekerjaannya, dan lain sebagainya (Nurendra \& Saraswati, 2016)

Pendapat yang sama juga disampaikan oleh Robbins \& Judge (2015) bahwa kepuasan kerja merupakan suatu respon terhadap pekerjaan seorang individu yang positif dan menjadi hasil dari evaluasi perkerjaan. Hal ini tampak dari karyawan yang memiliki pemikiran positif dalam pekerjaan dan berbagai hal yang dihadapai dilingkungannya. Berdasarkan penjelasan kepuasan kerja di atas, dijelaskan bahwa kepuasan kerja adalah suatu perasaan puas dan atau memuaskan yang berasal dari pencapaian yang telah dilakukan seorang individu dalam hal pekerjaannya.

Luthans (2011) menjelaskan bahwa terdapat beberapa indikator dalam pengukuran kepuasan kerja yaitu pekejaan itu sendiri, gaji, kesempatan promosi, pengawasan, dan rekan kerja. Merujuk pada Hasibuan (2001), kepuasan kerja dapat diukur melalui beberapa indikator yaitu rasa senang akan pekerjaannya, rasa cinta akan pekerjaannya, moral kerja, kedisiplinan, dan prestasi kerja.

\section{Hubungan antar Variabel}

Machuca et al. (2016), dalam penelitiannya mengenai hubungan antara work life balance dan kebanggaan organisasi dan kepuasan kerja, work life balance berpengaruh secara langsung terhadap kebanggan organisasi dan kepuasan kerja bagi karyawan. Nurendra \& Saraswati (2016) memperoleh hasil bahwa work life balance berpengaruh kekepuasan kerja. Hasil pengkajian lain yang sama juga diketahui bahwa work life balance terdapat pengaruh kekepuasan kerja signifikan positif. Menurut Omar \& Zakaria (2016), keseimbangan kehidupan kerja yang baik akan memengaruhi kepuasan kerja perawat wanita secara positif. Berbeda hal dengan Son \& Jung (2019) mengatakan bahwa work life balance memiliki pengaruh negatif terhadap kepuasan kerja.

\section{H1: Diduga work life balance berpengaruh positif terhadap kepuasan kerja.}

Tuğsal (2017) menyatakan bahwa faktor sosio demografis dan keseimbangan kehidupan kerja berpengaruh secara langsung pada kelelahan emosional karyawan. Kelelahan kerja secara emosional 
Cici Novita Sihaloho \& Nurul Indawati. Peran Mediasi Emotional Exhaustion pada Pengaruh Work Life Balance terhadap Kepuasan Kerja Karyawan Wanita di Universitas Negeri Surabaya

dipengaruhi oleh work life balance (Khairani, 2018). Fitriani (2019) mengatakan bahwa work life balance memiliki hubungan negatif ke kelelahan emosional karyawan di industri tekstil dan produk tekstil. Yunita (2018) mengatakan jika tingginya keseimbangan kehidupan kerja akan menyebabkan rendahnya kelelahan emosional. Berbeda dengan Hardiyono et.al (2019), hubungan dari work life balance ke kelelahan emosional bersifat positif.

H2: Diduga work life balance berpengaruh negatif terhadap emotional exhaustion.

Christianto \& Putra (2016) mengatakan bahwa kepuasan kerja karyawan dipengaruhi oleh salah satu aspek di antaranya yaitu emotional exhaustion. Menurut Sholikan (2015), kelelahan emosional memiliki pengaruh ke kepuasan kerja karyawan dan signifikan. Santika \& Sudibia (2017) berpendapat bahwa emotional exhaustion karyawan memiliki pengaruh ke kepuasan kerja, sedangkan Christianto \& Putra (2016), menjelaskan work life balance secara negatif berpengaruh terhadap kepuasan kerja karyawan di CV.Mahesa Company Group Denpasar. Hubungan antar variabel juga dapat dilihat di Gambar 1.

H3: Diduga emotional exhaustion berpengaruh negatif terhadap kepuasan kerja.

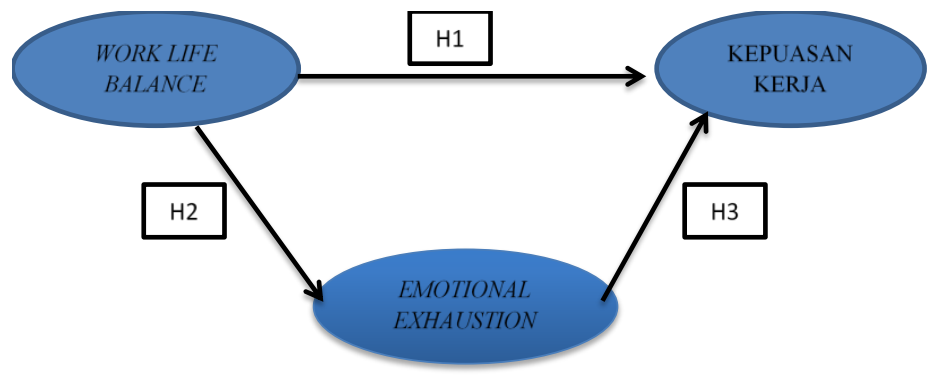

Gambar 1. KERANGKA BERPIKIR

\section{METODE PENELITIAN}

Penelitian ini merupakan penelitian kuantitatif, mengaplikasikan metode survei. Variabel bebas dalam penelitian ini adalah work life balance (X), variabel terikat adalah kepuasan kerja (Y), dan variabel Moderasi adalah emotion al exhaustion (Z). Populasi dalam penelitian ini merupakan karyawan wanita pada Universitas Negeri Surabaya. Dari hasil kuisoner yang disebar, diperoleh data sebanyak 60 karyawan wanita. Sampel berjumlah 60 diambil dari tenaga pendidik (dosen) dan tenaga kependidikan dengan mengaplikasikan teknik convenience sampling, di mana sampel diambil berdasarkan kesediaan elemen dan keleluasaan mendapatkan sampel tersebut. Sampel diambil pada tempat dan waktu yang tepat. Alat analisis penelitian ini menggunakan Structural Equation Model dengan bantuan software Smart Partial Least Square (PLS) 3.0.

\section{HASIL DAN PEMBAHASAN}

\section{Deskripsi Responden}

Berdasarkan hasil kuisioner yang terisi, diperoleh data mengenai jumlah dan sebaran responden. Dari diagram di atas dapat diketahui bahwa enam puluh responden berasal dari 7 (tujuh) fakultas yang ada di Universitas Negeri Surabaya. Sebaran tersebut dapat dilihat di Gambar 2. Rata-rata work life balance dari statistik mengindikasikan dari hasil indikator keseimbangan work life balance item X1.3 masuk kategori tinggi dengan nilai indikator 3, 23. Menjelaskan karyawan wanita di Universitas Negeri Surabaya memiliki aktivitas lain di luar pekerjaannya dan berkesempatan untuk berinteraksi dengan rekan di luar pekerjaan di Universitas Negeri Surabaya. Sedangkan hasil statistik rata-rata emotional exhaustion menjelaskan indikator tekanan waktu pada item Z1.2 tergolong kategori sedang dengan nilai indikator adalah 2, 13. Hal ini kemungkinan karena karyawan wanita di Universitas Negeri Surabaya masih merasa bahwa instansi memberikan pekerjaan dan dituntut untuk menyelesaikan dengan tenggang waktu yang diberikan oleh instansi. Hasil statistik rerata kepuasan 
kerja mengindikasikan bahwa hasil Pengawasan pada item pernyataan Y1.4 tergolong tinggi dengan nilai rerata indikator 3,60 Hal ini dapat diartikan bahwa dukungan dan kepercayaan akan tugas yang diberikan kepada karyawan wanita di Universitas Negeri Surabaya (Unesa) memberi pengaruh baik bagi pekerjaan karyawan tersebut sehingga ada semangat untuk pekerjaannya.

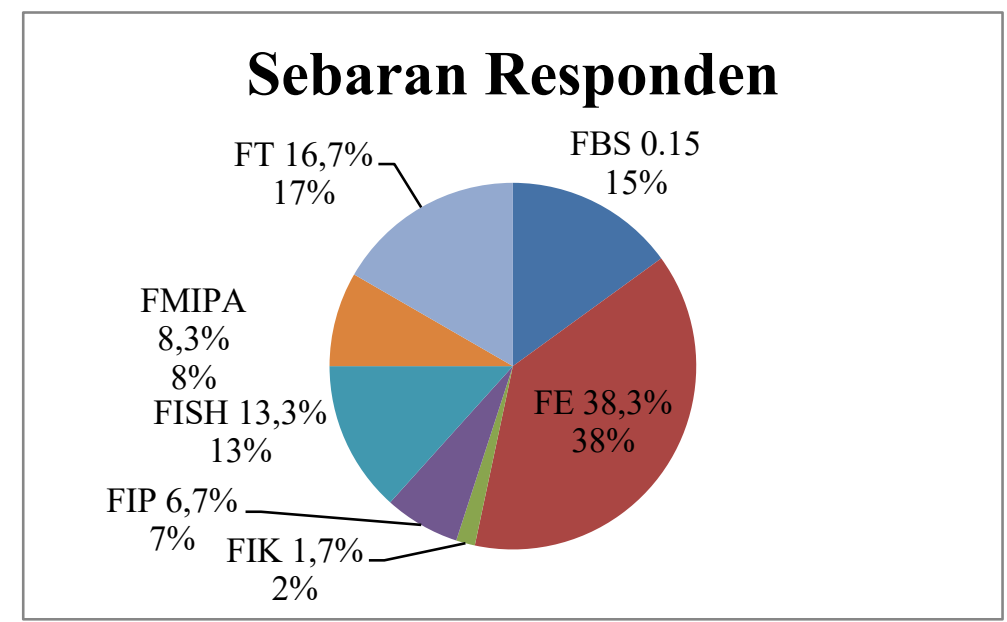

Gambar 2. SEBARAN RESPONDEN

\section{Uji Validitas dan Reabilitas}

Berdasarkan penjelasan data dalam tabel 1, tiap-tiap indikator variabel penelitian terdapat nilai outer loading $>0.5$, sehingga keseluruhan indikator akurat atau valid untuk digunakan. Nilai Cronbach's Alpha dapat digunakan apabila $>0,50$. Berdasarkan tabel 2, nilai keseluruhan konstruk dari model Cronbach's alpha berada $>0,50$. Dapat diartikan model variabel yang di atas telah memiliki tingkat reliabilitas yang kuat. Dalam penelitian ini, nilai koefisien diukur dengan menggunakan aplikasi olah data Smart PLS diperoleh dari bootstrapping. Untuk lebih jelasnya, berikut disajikan hasil koefisien jalur berdasarkan hasil kalkulasi bootstrapping melalui aplikasi olah data Smart PLS:

Tabel 1.

OUTER LOADING

\begin{tabular}{lcc}
\hline Variabel & Indikator & Outer Loading \\
\hline \multirow{3}{*}{ Work life balance $(\mathrm{X} 1)$} & $\mathrm{X} 1.1$ & 0.637 \\
& $\mathrm{X} 1.2$ & 0.528 \\
& $\mathrm{X} 1.3$ & 0.786 \\
& $\mathrm{X} 1.4$ & 0.746 \\
Emotional exhaustion $(\mathrm{Z})$ & $\mathrm{Z} 1.1$ & 0.627 \\
& $\mathrm{Z} 1.2$ & 0.871 \\
& $\mathrm{Z} 1.3$ & 0.515 \\
& $\mathrm{Z} 1.4$ & 0.702 \\
Kepuasan Kerja (Y) & $\mathrm{Y} 1.1$ & 0.614 \\
& $\mathrm{Y} 1.2$ & 0.714 \\
& $\mathrm{Y} 1.3$ & 0.679 \\
& $\mathrm{Y} 1.4$ & 0.527 \\
& $\mathrm{Y} 1.5$ & 0.632 \\
\hline
\end{tabular}

Sumber: Output PLS 3.0

Hubungan antar variabel pada tabel 3 dijelaskan sebagai berikut. Nilai t-statistic work life balance ke kepuasan kerja lebih besar dari t-tabel. Hal ini mengindikasikan adanya pengaruh variabel work life balance dan signifikan ke emotional exhaustion. Bertanda negatif artinya meningkatnya tingkat work life balance berdampak turunnya emotional exhaustion, begitu juga sebaliknya. 
Cici Novita Sihaloho \& Nurul Indawati. Peran Mediasi Emotional Exhaustion pada Pengaruh Work Life Balance terhadap Kepuasan Kerja Karyawan Wanita di Universitas Negeri Surabaya

Nilai t-statistics work life balance ke kepuasan kerja lebih besar dari t-tabel, mengindikasikan adanya pengaruh variabel work life balance ke kepuasan kerja secara signifikan. Bertanda positif yang mengindikasikan naiknya tingkat work life balance memengaruhi meningkatnya kepuasan kerja, segitupun sebaliknya.

Tabel 2.

\section{UJI REABILITAS}

\begin{tabular}{ll}
\hline \multicolumn{1}{c}{ Variabel } & \multicolumn{1}{c}{ Cronbach's Alpha } \\
\hline Work life balance & 0.608 \\
Emotional exhaustion & 0.639 \\
Kepuasan Kerja & 0.637 \\
\hline \multicolumn{2}{l}{ Sumber: Output PLS 3.0 }
\end{tabular}

Tabel 3. PATH COEFFICIENT

\begin{tabular}{lcccc}
\hline \multicolumn{1}{c}{ Hubungan antar Variabel } & Original Sample & T-statistics & \multicolumn{2}{c}{ Keterangan } \\
\hline $\begin{array}{l}\text { Work life balance ke emotional } \\
\text { exhaustion }\end{array}$ & -0.454 & 5.333 & $>1.96$ (Signifikan) & $\begin{array}{c}\text { Hipotesis } \\
\text { diterima }\end{array}$ \\
$\begin{array}{l}\text { Work life balance ke kepuasan kerja } \\
\begin{array}{l}\text { Emotional exhaution ke kepuasan } \\
\text { kerja }\end{array}\end{array}$ & 0.527 & 5.452 & $>1.96$ (Sigifikan) & $\begin{array}{c}\text { Hipotesis } \\
\text { diterima }\end{array}$ \\
\hline Surat & 0.072 & 0.586 & $\begin{array}{c}>1.96 \text { (tidak } \\
\text { signifikan) }\end{array}$ & $\begin{array}{c}\text { Hipotesis } \\
\text { ditolak }\end{array}$ \\
\hline
\end{tabular}

Sumber: Output PLS 3.0

Nilai t-statistics emotional exhaustion ke kepuasan kerja lebih kecil dari t-tabel, ini mengindikasikan tidak terdapat hubungan yang signifikan pada variabel emotional exhaustion terhadap kepuasan kerja. Bertanda positif mengindikasikan kepuasan kerja karyawan yang baik dihasilkan dari baiknya pula tingkat emotional exhaustion, begitu juga sebaliknya.

\section{Pengaruh Work Life Balance terhadap Kepuasan Kerja}

Berdasarkan hasil kajian didapatkan hasil bahwa work life balance berpegaruh secara signifikan positif ke Kepuasan Kerja karyawan, sehingga H1 diterima. Penelitian yang dilaksanakan oleh MasMachuca et al. (2015) memperkuat hasil kajian ini, menjelaskan bahwa work life balance karyawan signifikan positif berpengaruh kekebanggaan organisasi dan kepuasan kerja.

Jika diperoleh pengaruh positif signifikan mengindikasikan bahwa work life balance yang semakin baik memengaruhi pada meningkatnya kepuasan kerja karyawan. Hasil estimasi inner pengaruh work life balance ke kepuasan kerja bertanda positif. Menjelaskan work life balance adalah satu di antara yang ada faktor terpenting dalam meningkatkan Kepuasan Kerja karyawan wanita di Universitas Negeri Surabaya.

Melalui survei dan wawancara menjelaskan bahwa hampir karyawan merasa bahwa mereka bisa menyeimbangkan work life balance mereka, bisa dilihat nahwa karyawan masih bisa mengurusi pekerjaan dengan baik dan tepat waktu sekaligus mengurus kehidupan pribadinya, serta masih berkesempatan untuk melakukan kegemarannya di luar pekerjaannya.

Jawaban responden dari hasil analisis deskriptif variabel work life balance termasuk golongan tinggi ditinjau dari three box method. Artinya Work life balance mampu menjadi faktor kontekstual dalam meningkatkan kepuasan kerja karyawannya salah satunya, jelasnya peran setiap karyawan, memiliki aturan jam kerja yang baik, mampu membagi waktu dengan prioritas yang akibatnya dapat meningkatkan tingkat kepuasan kerja karyawan. Juga dapat diketahui dari nilai paling kecil salah satunya yaitu terdapat pada pernyataan yang menjelaskan dalam indikator Saya dapat menyeimbangkan antara pekerjaan dan hal lain dalam hidup saya. Hal itu berarti karyawan wanita 
merasa masih sedikit kurang mampu untuk menyeimbangkan pekerjaan dan kehidupan pribadinya, namun dari hasil pernyataan item memiliki nilai yang tergolong tinggi, hal itu mengindikasikan bahwa sebetulnya karyawan sudah mampu menyeimbangkan work life balance dengan adanya kebebasan karyawan wanita untuk melakukan kegiatan di luar pekerjaan dan bisa mengurusi anakanaknya sekaligus melakukan pekerjaan di Universitas Negeri Surabaya.

Mendukung penelitian Maslichah \& Hidayat (2017), keseimbangan work life balance yang baik akan menumbuhkan rasa puas terhadap pekerjaannya, timbulnya rasa bertanggungjawab penuh dalam kehidupan pribadi dan pekerjaan. Hal tersebut dapat diperkuat dengan tingginya tingkat kebebasan individu untuk melakukan pekerjaan yang diinginkan sekaligus mengurusi kehidupan pribadinya. Berdasarkan analisis di atas diartikan bahwa work life balance mampu memengaruhi kepuasan kerja karyawan wanita di Universitas Negeri Surabaya. Timbulnya kepuasan kerja pada setiap karyawan tidak terlepas dari baiknya tingkat work life balance.

\section{Pengaruh Work Life Balance terhadap Emotional Exhaustion}

Variabel work life balance berpengaruh negatif dan signifikan terhadap emotional exhasution yang diketahui dari hasil pengujian, sehingga H2 diterima. Hasil kajian Tuğsal (2017) menguatkan penelitian ini yang menjelaskan bahwa keseimbangan kehidupan kerja memiliki pengaruh negatif terhadap emotional exhaustion. Semakin rendahnya tingkat emotional exhaustion tidak terlepas pula dari semakin tingginya tingkat keseimbangan kehidupan kerja, hal ini berpengaruh negatif dan signifikan. Berdasarkan hasil estimasi inner model didapatkan hasil keseimbangan kehidupan kerja terhadap emotional exhaustion memiliki koefisien estimate bertanda negatif. Hasil tersebut dapat diketahui bahwa work life balance memiliki pengaruh signifikan ke emotional exhaustion karyawan wanita di Universitas Negeri Surabaya.

Semakin baik tingkat keseimbangan kehidupan kerja maka akan semakin turun pula tingkat emotional exhaustion karyawan, selain itu rendahnya tingkat emotional exhasution diakibatkan oleh tercapainya keseimbangan pekerjaan dan kehidupan pribadi karyawan wanita sehingga karyawan wanita tidak merasa bahwa instansi menekan mereka dalam hal pekerjaan yang berakibat timbulnya emotional exhaustion. Melalui hasil wawancara dan survei karyawan merasa bahagia dan senang ketika mereka mampu menyeimbangkan pekerjaan dan kehidupan pribadi mereka. karyawan masih bisa menyempatkan waktu untuk bekerja sekaligus menjalankan kehidupan pribadinya dan mempunyai waktu untuk melakukan hobinya sehingga membawa rasa senang saat bekerja dan mampu mengerjakan pekerjaannya tepat waktu. Apalagi jika instansi juga tidak menekan mereka dalam hal pekerjaan dan mempercayakan pekerjaan sepenuhnya kepada mereka.

Jawaban responden dari hasil analisis deskriptif variabel work life balance masuk dalam kategori sedang ditinjau dari three box method. Artinya work life balance memberikan rasa senang yang mengurangi tingkat emotional exhaustion dibuktikan dengan senangnya karyawan akan pekerjaannya karena bisa fokus mengerjakan pekerjaannya tanpa merasa khwawatir akan seimbang atau tidaknya bekerja di kantor dan menjalani kehidupannya sebagai individual.

Juga dapat diketahui dari nilai paling kecil salah satuya yaitu terdapat pada pernyataan yang menjelaskan dalam indikator stres kerja. Hal ini berarti karywan akan mengalami stres karena tidak bisa menyeimbangkan waktu saat bekerja dan kehidupan pribadi sehingga tidak bisa berfokus pada pekerjaannya yang mengakibatkan stres kerja apalagi jika instansi memberi beban kerja yang berlebihan sehingga kedua hal tersebut semakin sulit untuk dicapai. Berdasarkan analisis di atas diartikan jika karyawan wanita mampu menyeimbangkan pekerjaan dan kehidupan pribadi yang berdampak emotional exhaustion karyawan wanita di Universitas Negeri Surabaya.

\section{Pengaruh Emotional Exhaustion terhadap Kepuasan Kerja}

Variabel emotional exhaustion tidak signifikan dan adanya pengaruh ke kepuasan kerja, data tersebut diperolah dari hasil pengujian, sehingga H3 ditolak. Hasil penelitian Safrida et al. (2016) memperkuat pengkajian ini yang berpendapat bahwa kelelahan emosional terdapat pengaruh ke Kepuasan Kerja 
Cici Novita Sihaloho \& Nurul Indawati. Peran Mediasi Emotional Exhaustion pada Pengaruh Work Life Balance terhadap Kepuasan Kerja Karyawan Wanita di Universitas Negeri Surabaya

guru SMP 2 Medan. Variabel emotional exhasution dan kepuasan kerja digunakan dalam penelitian tersebut. Semakin tinggginya nilai tingkat kepuasan karyawan wanita tidak terlepas pula dari semakin baiknya tingkat work life balance karyawan wanita tersebut, hal tersebut memberikan pengaruh tidak signifikan dan positif.

Didapatkan hasil bahwa emotional exhaustion ke kepuasan kerja yang didasarkan dari estimasi inner model dengan koefisien estimate bertanda positif. Diartikan bahwa emotional exhaustion memiliki pengaruh signifikan ke kepuasan kerja karyawan wanita di Universitas Negeri Surabaya. Semakin baik tingkat emotional exhaustion akan memengaruhi kepuasan kerja karyawan, yaitu meningkatnya kepuasan kerja karyawan, tingginya tingkat emotional exhaustion yang ada pada teorinya memang akan menimbulkan rasa tidak puas pada pekerjaan, berbeda hal nya dengan karyawan wanita di Universitas Negeri Surabaya, mereka justru merasa puas akan pekerjaannya apabila tingkat emotional exhaustion tinggi, hal ini dikarenakan emotional exhaustion justru mengakibatkan karyawan wanita semakin fokus pada pekerjaannya, tidak merasa bahwa pekerjaan itu merupakan suatu beban dan pekerjaannya itu sendiri tidak berdampak pada stress kerja.

Variabel emotional exhaustion berkategori sedang ditinjau dari three box method yang merupakan hasil jawaban responden dari analisis deskriptif. Artinya, Emotional exhaustion memberikan rasa bertanggungjawab yang tinggi akan pekerjaan yang menimbulkan semakin puasnya karyawan wanita akan pekerjaannya. Juga dapat diketahui dari nilai paling kecil salah satunya yaitu terdapat pada pernyataan yang menjelaskan dalam indikator pekerjaan itu sendiri. Hal ini berarti karyawan akan mengalami ketidakpuasan kerja jika merasa bekerja itu hanya menjalankan tugas saja dan tidak digunakan sebagai cara untuk menerima tanggungjawab pada pekerjaan itu sendiri. Berdasarkan analisis di atas dapat diketahui bahwa karyawan wanita telah mampu dan merasa puas pada pekerjaannya sekalipun dipengaruhi oleh emotional exhaustion.

\section{Pengaruh Work life balance terhadap Kepuasan Kerja melalui Emotional exhaustion}

Dijelaskan dalam studi terdahulu dari beberapa ahli bahwa dapat diketahui jika variabel mediasi bisa menjadi pengaruh secara perfect mediation maupun partial mediation. Dari hasil uji hipotesis, dapat ditunjukkan bahwa emotional exhaustion secara tidak langsung memediasi pengaruh work life balance terhadap kepuasan kerja, sehingga $\mathrm{H} 4$ diterima. Ini menunjukkan bahwa work life balance secara langsung berpengaruh terhadap kepuasan kerja, dan secara tidak langsung dapat berpengaruh terhadap kepuasan kerja melalui emotional exhaustion.

Hasil perhitungan di atas didapatkan pengaruh positif hubungan work life balance pada kepuasan kerja melalui emotional exhasution secara signifikan. Hasil penelitian ini menjelaskan bahwa pengaruh langsung lebih besar daripada pengaruh tidak langsung. Emotional exhaustion yang dimiliki karyawan wanita atas work life balance yang ada pada instansi akan berdampak pada rasa puas akan setiap pekerjaan dari setiap karyawan wanita. Hal ini dapat memberi suatu informasi bahwa emotional exhaustion terhadap pekerjaan dapat dirasa oleh karyawan wanita akan berdampak positif dan signifikan pada hubungan work life balance dengan kepuasan kerja.

\section{KESIMPULAN}

Work life balance signifikan positif berpengaruh kepuasan kerja karyawan wanita di Universitas Negeri Surabaya. Work life balance signifikan negatif memiliki pengaruh terhadap emotional exhaustion karyawan wanita di Universitas Negeri Surabaya. Emotional exhaustion tidak terbukti berpengaruh ke kepuasan kerja karyawan wanita di Universitas negeri Surabaya. Work life balance signifikan dan positif berpengaruh ke kepuasan kerja melalui emotional exhaustion pada karyawan wanita di Universitas Negeri Surabaya. Karyawan wanita Universitas Negeri Surabaya telah menerapkan sistem kerja yang jelas dan tersruktur serta dampaknya terjadi peningkatan kepuasan kerja. karyawan wanita Universitas Negeri Surabaya telah menerapkan sistem kerja yang jelas dan tersruktur serta dampaknya terjadi penurunan tingkat emotional exhaustion. karyawan wanita Universitas Negeri Surabaya memiliki tingkat emotional exhaustion yang tinggi yang berdampak meningkatkan kepuasan kerja karena rasa bertanggung jawab akan pekerjaan itu sendiri. Instansi perlu 
menerapkan sistem kerja yang jelas agar karyawan bisa membagi waktu kerja dan memprioritaskan hal-hal yang dianggap lebih penting agar tidak memicu timbulnya kelelahan secara emosional dan meningkatkan kepuasan kerja. Penelitian ini memiliki keterbatasan dalam penelitian, yaitu hanya meneliti karyawan wanita, diharapkan di penelitian lain dapat meneliti seluruh karyawan.

\section{DAFTAR PUSTAKA}

Akbar, D. A. (2017). Konflik Peran Ganda Karyawan Wanita dan Stres Kerja. Jurnal. Kajian. Gender. Anak An Nisa'a 12, 33-48.

Al Momani, H. M. (2017). The Mediating Effect of Organizational Commitment on the Relationship betweenWork-life Balance and Intention to Leave: Evidence from Working Women in Jordan. International Business Research, 10(6), 164. https://doi.org/10.5539/ibr.v10n6p164.

Allen, M. A. M. (2015). Competencies of older workers and its influence on career success and job satisfaction. International. Journal. 37, 1-37.

Andrade, M. S., Westover, J. H. \& Kupka, B. A. (2019). The Role of Work-Life Balance and Worker Scheduling Flexibility in Predicting Global Comparative Job Satisfaction. International. Journal. Human. Resource. Studies. 9, 80.

Anuradha \& Pandey, M. (2016). Impact of work-life balance on job satisfaction of women doctors. Problem. Perspective. Management. 14, 0-6.

Arika. (2018). Pengaruh Work Life Balance terhadap kepuasan kerja di PT X. Journal. Materials. Processing. Technology.1, 1-8.

Arunika MMA, kottawatta H. (2015). The Effect of Work Life Balance on Employee Job Satisfaction among Non Executives in the Public Banking Sector in Colombo District. Human. Resources. Management. Journal. 03, 60-71.

Asepta, U. Y. \& Maruno, S. H. P. (2017). Analisis Pengaruh Work-Life Balance Dan Pengembangan Karir Terhadap Kepuasan Kerja Karyawan PT.Telkomsel, Tbk Branch Malang. Jurnal. Ilmu. Bisnis. Ekonomi. Asia 11, 77-85.

Bintang, S. K. \& Dewi Puri Astiti. (2011). Work-Life Balance Dan Intensi Turnover Pada Pekerja Wanita Bali Di Desa Adat Sading, Mangupura, Badung. Jurnal. Psikologi. Udayana 2, 188206.

BPS. (2018). Berita Resmi Statistik Keadaan Ketenagakerjaan Indonesia Februari 2018. Diakses pada 31 Oktober 2019, dikutip dari https://www.bps.go.id/subject/6/tenaga-kerja.html.

Bruce, S.P. (2009). Recognizing Stress and Avoiding Burnout, Currents In Pharmacy Teaching ang Learning Journal, Vol. 1; pp57-64.

Bushra, A. Impact of work life balance on job satisfaction and organisation commitment among university teachers. International. Journal of. Multidisciplinary. Science. Engineering. 5, 443457 (2014).

Christianto, G. \& Putra, M. (2016). Pengaruh Emotional exhaustion Dan Motivasi Kerja Terhadap Kepuasan Kerja Karyawan. E-Jurnal Manajemen. Universitas. Udayana 5, 2786-2813.

Darmawan et al. (2015). Hubungan Burnout dengan Work-Life Balance pada Dosen Wanita. Jurnal. Mediapsi 01, 28-39. 
Cici Novita Sihaloho \& Nurul Indawati. Peran Mediasi Emotional Exhaustion pada Pengaruh Work Life Balance terhadap Kepuasan Kerja Karyawan Wanita di Universitas Negeri Surabaya

Fajar, M. W. (2019). Pengaruh iklim psikologis terhadap kinerja karyawan melalui kepuasan kerja pada karyawan PT. Rosan Permai Sidoarjo. SSRN Electron. Journal. 5, 1-19.

Ferdinand, A. (2006). Metode Penelitian Manajemen. Semarang: Badan Penerbit Universitas Diponegoro.

Fitriyani, A. R. I. (2019). Hubungan antara keseimbangan kehidupan kerja dan dukungan sosial dengan burnout pada karyawan. Jurnal. Psikologi. Surakarta 8.

Ganapathi, Devan, I. M., Gilang \& Alini. (2016). Pengaruh Work-Life Balance Terhadap Kepuasan Kerja Karyawan (Studi Pada Pt . Bio Farma Persero). E-Proceeding Management. 3, 506-511.

Ghozali, I. (2015). Partial Least Square: Konsep, Teknik dan Aplikasi menggunakan program PLS $\left(2^{\text {th }} E d\right)$. Badan Penerbit Universitas Diponegoro.

Goyena, R. \& Fallis, A. (2019). Pengaruh Work life Balance terhadap Kepuasan Kerja. Journal. Chemical. Information. Modelling. 53, 1689-1699.

Hadi, H. K. (2013). Pengaruh work-family conflict terhadap performa kerja petugas pemadam kebakaran pada Dinas PMK Surabaya. Jurnal. Bisnis dan Manajemen. Vol. 6 No. 1 Agustus 13, $43-51$.

Hasibuan, Malayu. (2001). Manajemen Sumber Daya Manusia. Jakarta: Bumiaksara.

Houkes, I., Janssen, P. P. M., Jonge, J. De \& Bakker, A. B. (2003). Specific determinants of intrinsic work motivation, emotional exhaustion and turnover intention: A multisample longitudinal study. Journal. Occupational. Organization. Psychology. 427-450.

Iswardhani, I., Brasit, N. \& Mardina, R. (2019). Pengaruh Work-Life Balance dan Burnout terhadap Kepuasan Kerja Karyawan The Effect of Work-Life Balance and Burnout on Employee Job Satisfaction. Hasanuddin Jurnal. Business. Strategy. 1-13.

Jabeen, F., Friesen, H. L. \& Ghoudi, K. (2018). Quality of work life of Emirati women and its influence on job satisfaction and turnover intention: evidence from the UAE. Journal. Organization. Change. Management. Organization. Development. Journal. Iss Leadership. \&amp Organization. Development. Journal. 3, 349-361.

Junaidin, Ikhram, A. A. \& Hardiyono. (2019). Pengaruh Work Life Balance Terhadap Burnout Dan Kepuasan Kerja Karyawan (Studi Kasus Pada Perusahaan Listrik Negara (PLN) Area Makassar Selatan). MANDAR (Management. Development. Appllied. Research. Journal) 1, $27-34$.

Khairani, N. (2018). Hubungan antara keseimbangan kerja dengan kelelahan kerja pada perawat wanita yang telah menikah. Journal. Petrology. 369, 1689-1699.

Langford, P. H. (2009). Measuring organisational climate and employee engagement: Evidence: For a 7 Ps model of work practices and outcomes. Australian Journal of Psychology, 61(4), 185-198. https://doi.org/10.1080/00049530802579481.

Luthans, F. (2011). Organizational Behavior. New York: McGraw Hill

Mardhatillah, A. \& Santoso, A. S. (2019). Implementasi Work Life Balance Dalam Kehidupan Sehari-Hari. Jurnal. Abdi Masyarakat. 5, 41.

Maslach, C. \& Jackson, S. E. (1981). The measurement of experienced burnout. Journal. Organizational. Behaviour. 2, 99-113. 
Maslach, C., Schaufeli, W. B. \& Leiter, M. P. (2001). Job Burnout. Annual. Reviews. Psychology. $397-422$.

Maslichah N. I \& Hidayat, K. (2017). Kepuasan kerja karyawan (Studi pada Perawat RS Lavalette Malang Tahun 2016). Jurnal. Administrasi. Bisnis 49, 60-68.

Mas Machuca, M., Berbegal-Mirabent, J. \& Alegre, I. (2016). Work-life balance and its relationship with organizational pride and job satisfaction. Journal. Managerial. Psychology. 31, 586-602.

Malik, M. I., Gomez, S. F., Ahmad, M. \& Saif, M. I. (2010). Examining the relationship of work life balance, job satisfaction and turnover in Pakistan. Foundation. University. Islam.Journal. 2, $27-33$.

Moorhead, G., \& Griffin, R. W. (2013). Perilaku Organisasi. Jakarta: Salemba Empat.

Mujiatun, S., Jufrizen, J. \& Ritonga, P. (2019). Model Kelelahan Emosional: Antaseden Dan Dampaknya Terhadap Kepuasan Kerja Dan Komitmen Organisasi Dosen. Jurnal. Ilmu. Manajemen. 9, 447.

Nafiudin. (2015). Pengaruh Work Life Balance Dan Kepuasan Kerja Terhadap Turnover Intention Karyawan Pada PT Bank Agroniaga Tbk Cabang Bandung. Jurnal. Sains Manajemen. 1, 53.

Nasekhah, A. D. (2019). Pengaruh Peran Ganda Terhadap Kinerja Karyawan Wanita Di Tempat Kerja Di Lpp Rri Yogyakarta. Diklus Jurnal. Pendidikan. Luar Sekolah. 1, 137-149.

Nirmalasari, I., (2014). Manajemen, M. \& Maret, U. S. Analisis Pengaruh Work Life Balance Terhadap Komitmen Organisasi Melalui. Jurnal. Ekonomi. Bisnis 2.

Nujjiya, T. M., (2015). Fakultas Psikologi, F., Islam, U. \& Syarif, N. Transformasional, Dan Faktor Deomografis Terhadap Work-Life Balance. Jurnal. Psokologi 2.

Nurendra, A. M. \& Saraswati, M. P. (2019). Model peranan Work life balance, Stres kerja dan Kepuasan kerja pada karyawan. Journal. Chemical. Information. Modelling. 53, 1689-1699.

Oktaviani, H. (2018). Pengaruh Work Life Balance Dan Perceived Organizational Support Terhadap Turnover Intention Melalui Organizational Commitment Sebagai Variabel Intervening Pada PT Berlian Jasa Terminal Indonesia. Jurnal. Ilmu. Manajemen. 2.

Omar, M. K. Bin \& Zakaria, A. (2016). Work-Life Balance and Job Satisfaction among Malaysian Healthcare Employees. Environment. Proceedings. Journal. 1, 271.

Poulose, S., \& N, Sudarsan. (2014). Work Life Balance: A Conceptual Riview. International. Journal of. Advances Management and Economics. Vol. 3 Issue.2, 5-9.

Rahman, M. F. (2019). Quality of Services and Satisfaction of Customer: Mediated by Consumer Buying Decision Benchmark sensitivity in performance evaluation of funds View project SMEs Performance in Pakistan View project Quality of Services and Satisfaction of Customer: Mediated. European. Journal. Business. Management. 11, 183-189.

Robbins, S. P. dan Judge, T. A. (2015). Perilaku Organisasi. Edisi 16. Jakarta: Salemba Empat.

Safrida, S., Supriadi, S., Nasution, I. \& Fahmi, N. A. (2019). Variabel Anteseden Kepuasan Kerja Dan Dampaknya Terhadap Komitmen Organisasi Di Smp Negeri 2 Medan. Jurnal. Development. 3, 12. 
Cici Novita Sihaloho \& Nurul Indawati. Peran Mediasi Emotional Exhaustion pada Pengaruh Work Life Balance terhadap Kepuasan Kerja Karyawan Wanita di Universitas Negeri Surabaya

Santika, P. B. \& Sudibia, G. A. (2017). Pengaruh kelelahan emosional terhadap kepuasan kerja dan komitmen organisasional. Jurnal. Manajemen. Udayana 6, 634-662.

Shabrina, D. \& Ratnaningsih, Z. (2019). Hubungan Antara Work Life Balance Dengan Kepuasan Kerja Pada Karyawan PT. Pertani (Persero). Jurnal. Empati 8, 27-32.

Sholikhan. (2009). Kepuasan Kerja Dan Dampaknya Terhadap Kinerja Guru. Jurnal. Ekonomi. Moderenisasi. 238-253.

Schabracq, M. J., \& Cooper, C. L. (2003). The Handbook of Work and Health Psychology. Science, xiv, 362 p. England: John Willey and Sons.

Singh, P. and Khanna, P. (2011). Work-Lefe Balance: A Tool for Increased Employee Productivity and Retention. Lachoo Management Journal.Vol. 2, No. 2, pp. 188-206.

Son, D. M. \& Jung, Y.-I. (2019). The Effect of Work-Life Balance on Job Satisfaction and Turnover Intention of Hospital Nurses: Compared to Female Wage Workers. Korea. National. University. Jurnal. 27, 268-276.

Tjiong Fei Lie dan Hotlan Siagian. (2018). Pengaruh Kepuasan Kerja Terhadap Kinerja Karyawan Melalui Motivasi Kerja pada CV. Union Event Planner. Jurnal. Agora 6.

Tuğsal, T. (2017). The effects of socio-demographic factors and work-life balance on employees' emotional exhaustion. Journal. Human. Sciences. 14, 653.

Tumbel, T. M. et. al. (2017). Pengaruh Work-Life Balance Dan Burnout Terhadap Kepuasan Kerja. Jurnal. Administrasi Bisnis 5, 1-8.

Ummah, W. \& Novianti, N. P. (2018) Work Life Balance ditinjau dari modal psikologis pekerja di Perusahaan Garmen Yogyakarta. Jurnal. Universitas. Islam. Indonesia. (5)2, 285-299.

Wright, T. A. \& Cropanzano, R. (1998). Emotional exhaustion as a predictor of job performance and voluntary turnover. Journal. Applied. Psychology. 83, 486-493.

Yüksel, C. Kaçan., Örsal, Ö. \& Nedime, Köşgeroğlu. (2016). Determination of Job Satisfaction Levels Among Nurses Cevriye. Journal. Nursing. Research. Development. 18, 1-12.

Yuliastini, N. \& Putra, M. (2015). Pengaruh Kelelahan Emosional Terhadap Kepuasan Kerja Guru Smk Di Denpasar. E-Jurnal Manajemen. Universitas. Udayana 4, 943-959.

Yunita, P. I. (2018). Menciptakan Keseimbangan Antara Pekerjaan Dan Kehidupan (Work-Life Balance): Apakah Faktor Situasional Pekerjaan Berpengaruh? Jurnal. Ilmiah. Manajemen. Bisnis 3, 135-144. 